\title{
Comparative Kinetics of Iron Ore Dissolution in Aqueous $\mathrm{HCl}-\mathrm{HNO}_{3}$ System
}

\author{
Onyedika Gerald ${ }^{*}$, Nwoko Christopher, Oguarah Ayebatonworio, Ogwuegbu Martin \\ Mineral Processing Unit, Department of Chemistry, Federal University of Technology, Owerri, Nigeria \\ Email: "gonyedik@mtu.edu
}

Received April 2, 2013; revised May 4, 2013; accepted May 16, 2013

Copyright (C) 2013 Onyedika Gerald et al. This is an open access article distributed under the Creative Commons Attribution License, which permits unrestricted use, distribution, and reproduction in any medium, provided the original work is properly cited.

\begin{abstract}
The dissolution kinetics of the dissolution of iron ore in aqueous $\mathrm{HCl} / \mathrm{HNO}_{3}$ solution was studied. The elemental composition of the ore was carried out using the inductively coupled plasma-optical emission spectrophotometer (ICP-OES). The result showed that the iron ore contain; Fe (62.1\%), O (21.7\%), Cu (11.1\%), Mg (2.39\%), Na (1.51\%), Mn (1.47\%), $\mathrm{K}(0.78 \%), \mathrm{Ca}(0.58 \%)$ and $\mathrm{Zn}(0.01 \%)$. It was determined that the dissolution rate increased with increased solution concentration, temperature, time and decreased particle size of the ore. The optimum conditions for effective dissolution of $88 \%$ of the iron ore were found to be $8 \mathrm{M}$ of the solution, $353 \mathrm{~K}, 100 \mathrm{~min}$ and ore particle size of less than $75 \mu \mathrm{m}$. The kinetic evaluation of the dissolution process was studied using three different shrinking core models (SCM); Film diffusion: $\mathrm{k}_{\mathrm{f}} \mathrm{t}=X_{B}$; interfacial chemical reaction $\mathrm{k}_{\mathrm{r}} \mathrm{t}=1-\left(1-X_{B}\right)^{1 / 3}$ and ash/product layer diffusion: $\mathrm{k}_{\mathrm{d}} \mathrm{t}=$ $1-\frac{2 X_{B}}{3}-\left(1-X_{B}\right)^{2 / 3}$ for spherical materials was performed. The results obtained showed that the rate determining step
\end{abstract} for the dissolution process was the product layer diffusion and therefore, the reaction followed this mechanism. The apparent activation energy (Ea) and the order of reaction were found to be $20.48 \mathrm{~kJ} / \mathrm{mol}$ and 0.7 respectively.

Keywords: Kinetics; Dissolution; Iron Ore; Shrinkage Core Model

\section{Introduction}

Dissolution processes have been extensively utilized to separate valuable minerals from their ores. Several researches [1-5] have been carried out on either the dissolution or both the dissolution and kinetic study of iron ore in different reagents such as $\mathrm{HCl}, \mathrm{H}_{2} \mathrm{SO}_{4}$, oxalic acid et cetera. It was observed that the dissolution of iron ore or even the extraction of iron from an ore containing it increases as the concentration, temperature, time and stirring speed increases but decreases as the particle size increases due to its decreasing surface area [3-5]. Baba et $a l$. [1,2] observed that iron ore dissolves easily and more efficiently in $\mathrm{HCl}$ than in $\mathrm{H}_{2} \mathrm{SO}_{4}$ or $\mathrm{HNO}_{3}$ and it was believed to be as a result of ferric-chloride complexes formation. It therefore required less energy for the reaction to occur comparing the activation energies of 13.63 $\mathrm{kJ} / \mathrm{mol}$ in $\mathrm{HCl}$ and $38.29 \mathrm{~kJ} / \mathrm{mol}$ in $\mathrm{H}_{2} \mathrm{SO}_{4}$ respectively. The kinetic study of these dissolutions reaction processes

"Corresponding author. were carried out using the shrinking core models to interpret the processes involved in either the leaching or dissolution $[1,3,4,6]$. During the leaching process, three major steps occur; diffusion or mass transfer through the liquid film surrounding a solid particle, chemical reaction on the surface of the un-reacted core, and diffusion through the ash/inert solid layer. The slowest between these steps is considered the rate determining step. The model first developed by Yagi and Kunii [6-8] helped to derive the rate determining step from the experimental data using the equations below:

$$
\begin{gathered}
X=3 \mathrm{~K}_{\mathrm{g}} \mathrm{M}_{\mathrm{s}} \mathrm{C}_{\mathrm{At}} / \mathrm{a} \rho \mathrm{sr}_{0}=\mathrm{k}_{\mathrm{f}} \mathrm{t} \\
1-\frac{2 X_{B}}{3}-\left(1-X_{B}\right)^{2 / 3}=2 \mathrm{M}_{\mathrm{s}} \mathrm{DC}_{\mathrm{At}} / \mathrm{a} \rho_{\mathrm{s}} \mathrm{r}_{0}^{2}=\mathrm{k}_{\mathrm{d}} \mathrm{t} \\
1-\left(1-X_{B}\right)^{1 / 3}=\mathrm{K}^{\prime \prime} \mathrm{M}_{\mathrm{s}} \mathrm{C}_{\mathrm{At}} / \mathrm{a} \rho_{\mathrm{s}} \mathrm{r}_{0}=\mathrm{k}_{\mathrm{r}} \mathrm{t}
\end{gathered}
$$

where $\mathrm{K}_{\mathrm{f}}, \mathrm{K}_{\mathrm{d}}$, and $\mathrm{K}_{\mathrm{r}}$ are the rate constants for the liquid film diffusion, ash/inert solid layer diffusion, and surface chemical reaction respectively. $X_{B}$ is the fraction reacted, 
$\mathrm{M}_{\mathrm{S}}$ is the molecular weight of the solid, $\mathrm{C}_{\mathrm{A}}$ is the concentration of the dissolved lixiviant $\mathrm{A}$ in the bulk of the solution, "a" is the stoichiometric coefficient of reagent in the leaching reaction, $\mathrm{r}_{0}$ is the initial radius of the solid particle, $\rho_{\mathrm{s}}$ is the density of the solid, $\mathrm{D}$ is the diffusion coefficient in the porous product layer, $\mathrm{K}_{\mathrm{g}}$ is the mass transfer coefficient between fluid and solid particle, "K" is the first-order rate constant for the surface reaction and $t$ is the contact time. This research work is intended to study the dissolution of iron ore in a $3: 1 \mathrm{HCl}-\mathrm{HNO}_{3}$ system (similar to aqua regia) which is a well known reagent for dissolving un-reactive metal minerals such as gold, silver, et cetera and also the kinetic evaluation using three different shrinking core models (SCM). So far, there is no data to this effect viz-a-viz the use of Nigerian iron ore is concerned.

\section{Materials and Methods}

\subsection{Materials}

Iron ore from the Toto Muro iron ore deposit in Nasarawa State of Nigeria was used for this study. Chemical analysis of the sample ore was done with Leeman Model of Inductively coupled plasma-optical emission spectrophotometer. Different particle sizes $(<75 \mu \mathrm{m}, 75 \mu \mathrm{m}, 125$ $\mu \mathrm{m}$ and $150 \mu \mathrm{m}$ ) were obtained with the use of 8 inch diameter size mechanical sieve shaker. Distilled water and analytical grade chemicals (BDH) were used as provided to prepare all the solutions.

\subsection{Methods}

Particle sizes of less than $75 \mu \mathrm{m}$ sample of the iron ore was used for the experiment at a constant concentration $\mathrm{HCl}-\mathrm{HNO}_{3}$ solution and a fixed temperature of $331 \mathrm{~K}$ but at different contact time. $1.0 \mathrm{~g}$ of the given particle size sieve sample was weighed and then transferred into a 250 $\mathrm{ml}$ beaker containing $15 \mathrm{ml}$ of $8 \mathrm{M} \mathrm{HCl}$ and $5 \mathrm{ml}$ of $8 \mathrm{M}$ $\mathrm{HNO}_{3}$ and made to $100 \mathrm{ml}$ with distilled water. The mixture was agitated manually with a glass stirrer. The mixture was stirred and heated to $331 \mathrm{~K}$ for various contact times of 20,30, 60 and $100 \mathrm{~min}$. At the end of each period, the solution was cooled and filtered into a $100 \mathrm{ml}$ standard flask and analyzed.

The same procedure was also repeated for different acid $\left(\mathrm{HCl}-\mathrm{HNO}_{3}\right)$ concentrations of $4 \mathrm{M}, 2 \mathrm{M}$ and $1 \mathrm{M}$ at $331 \mathrm{~K}$ for 20, 30, 60 and $100 \mathrm{~min}$. This same procedure described above was repeated for $343 \mathrm{~K}$ and $353 \mathrm{~K}$ for $20,30,60$ and $100 \mathrm{~min}$ with $8 \mathrm{M}$ acid concentration. The following particle size fractions were examined $75 \mu \mathrm{m}$, $125 \mu \mathrm{m}$ and $150 \mu \mathrm{m}$ at a fixed temperature of $353 \mathrm{~K}$ for $30 \mathrm{~min}$ with $8 \mathrm{M}$ acid concentration. The kinetics of the ore dissolution was also investigated for the effects of temperature, acid concentration, particle size and contact time.

\section{Results and Discussion}

\subsection{Chemical Analysis}

The iron ore was analyzed chemically using the inductively coupled plasma-optical emission spectrophotometer and the results are shown in Table 1. The primary elements found in the sample included $62.10 \% \mathrm{Fe}, 21.7 \% \mathrm{O}$, $11 \% \mathrm{Cu}$. Other elements such as $\mathrm{Mn}, \mathrm{Mg}, \mathrm{K}, \mathrm{Ca}$ et cetera make up the $5.2 \%$ of the sample. From these analytical results, it is concluded that the ore was an iron ore.

\subsection{Effect of Acid Concentration}

The effect of 3:1 $\mathrm{HCl}-\mathrm{HNO}_{3}$ solution concentration on the dissolution of the iron ore was studied using the following concentrations; $1 \mathrm{M}, 2 \mathrm{M}, 4 \mathrm{M}$, and $8 \mathrm{M}$. Figure 1 is the graphical presentation of the result. From the figure, it can be seen that the iron dissolution rate increases as the concentration of the $\mathrm{HCl}-\mathrm{HNO}_{3}$ system increases from $1 \mathrm{M}$ to $8 \mathrm{M}$ at the same contact time. The optimum dissolution of $81 \%$ iron was achieved at the system concentration of $8 \mathrm{M}$.

\subsection{Effect of Temperature and Time}

The effects of temperature and contact time on iron dissolution were studied at varying temperatures $(331 \mathrm{~K}$, $343 \mathrm{~K}$ and $353 \mathrm{~K}$ ) and at varying time ( $20 \mathrm{~min}, 30 \mathrm{~min}$, $60 \mathrm{~min}$, and $100 \mathrm{~min}$ ). The results are shown in Figure 2. From Figure 2 it is observed that as the temperature increases, dissolution of the iron increased with tempera-

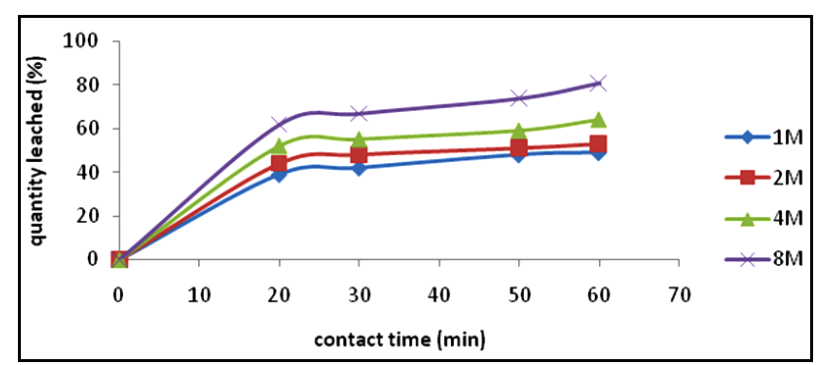

Figure 1. A graph of quantity of iron leached (\%) vs contact time (min) with respect to concentration [particle size, $<75$ $\mu \mathrm{m}$; temperature, $351 \mathrm{~K}$; mass of ore, $1 \mathrm{~g}$ ].

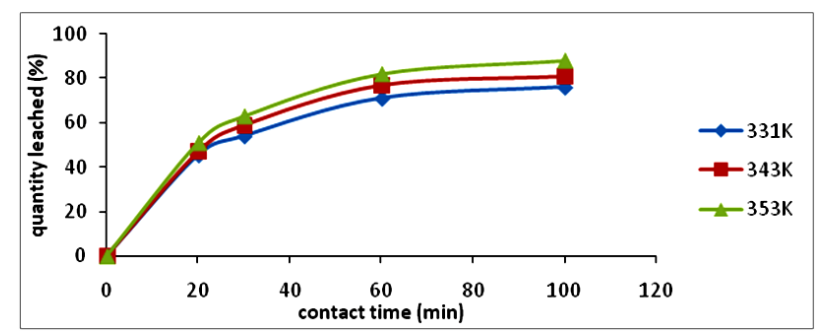

Figure 2. A graph of iron leached (\%) vs contact time (min) with respect to temperature [particle size, $<75 \mu \mathrm{m}$; conc., 8 M; mass of ore, $1 \mathrm{~g}]$. 
Table 1. Elemental analysis of the iron ore sample.

\begin{tabular}{cccccccccccc}
\hline Elements & $\mathrm{Fe}$ & $\mathrm{Cu}$ & $\mathrm{Mn}$ & $\mathrm{Mg}$ & $\mathrm{Ca}$ & $\mathrm{Zn}$ & $\mathrm{Na}$ & $\mathrm{K}$ & $\mathrm{O}$ & $\mathrm{Others}$ \\
\hline \% composition & 62.1 & 11.1 & 1.47 & 2.39 & 0.38 & 0.01 & 1.51 & 0.78 & 21.7 & 2.17 \\
\hline
\end{tabular}

ture and period of contact. When the temperature was increased from $331 \mathrm{~K}$ to $343 \mathrm{~K}$ at a particular period (20 min) only $2.5 \%$ increase in the quantity of iron leached was achieved. At temperature $331 \mathrm{~K}$, there was $8.5 \%$ increase in the quantity of iron leached. Optimum temperature and period was found to be $353 \mathrm{~K}$ and $100 \mathrm{~min}$ respectively in which $88 \%$ of the iron was leached.

\subsection{Effect of Particle Size}

Table 2 shows the experimental data when different particle sizes were investigated at $8 \mathrm{M} \mathrm{HCl}-\mathrm{HNO}_{3}$ solution, temperature of $353 \mathrm{~K}$ and contact time of $60 \mathrm{~min}$. Four particle sizes were studied $-<75 \mu \mathrm{m}, 75 \mu \mathrm{m}, 125 \mu \mathrm{m}$ and $150 \mu \mathrm{m}$ and from the data it was observed that the smallest particle size $(<75 \mu \mathrm{m})$ gave the highest percentage of iron leached (87\%) which is expected due to higher surface area for smaller particle size.

\subsection{Kinetic Analysis}

The dissolution of the iron ore under study was analyzed using the shrinking core model (SCM) based on the assumption that the material is spherical $[3,6,9]$ and the linearization of a plot of iron dissolved at various temperature and at various contact time was investigated using the three common shrinking core model for spherical material [6]. The Equations (1), (2), and (3) for the models are; $\mathrm{k}_{\mathrm{f}} \mathrm{t}=X_{B}, \mathrm{k}_{\mathrm{d}} \mathrm{t}=1-2_{3}^{X_{B}}-\left(1-X_{B}\right)^{2 / 3}$,

$\mathrm{k}_{\mathrm{r}} \mathrm{t}=1-\left(1-X_{B}\right)^{1 / 3}$ respectively used to test the best fit for the experimental data in which the slowest step is the rate determining step. Where Equations (1)-(3) are film diffusion control mechanism, interfacial chemical reaction control mechanism and ash/product layer diffusion control mechanism respectively with $\mathrm{k}_{\mathrm{f}}, \mathrm{k}_{\mathrm{r}}$ and $\mathrm{k}_{\mathrm{d}}$ as their respective rate constants, $\mathrm{t}$ is contact time and $X_{B}$ is the fraction of iron leached. The activation energy and the order of reaction were also calculated.

\subsection{Determination of the Reaction Mechanism}

The fraction of iron dissolved $\left(X_{B}\right)$ obtained from the Figure 2 with respect to the various contact time for various temperature was substituted into Equations (1)-(3) and the results are recorded in Table 3. The respective plots of the film diffusion, interfacial chemical reaction and product/ash layer diffusion control mechanisms vs contact time with respect to temperature is given in Figures 3-5. Table 4 give a comparative values of the rate
Table 2. Percentage of iron leached at varying particle sizes. [Temp., $353 \mathrm{~K}$; contact time, $60 \mathrm{~min}$; mass of ore, $1 \mathrm{~g}$ ].

\begin{tabular}{ccccc}
\hline Particle size $(\mu \mathrm{m})$ & $<75$ & 75 & 125 & 150 \\
\hline Percentage iron leached $(\%)$ & 87 & 82 & 62 & 55 \\
\hline
\end{tabular}

constants $k_{f}, k_{r}$ and $k_{d}$ and their respective regression correlation coefficients $\left(\mathrm{R}^{2}\right)$. From the values of the apparent rate constants and their respective $R^{2}$ values, it is observed that the experimental data best fit the product/ash layer diffusion control mechanism and therefore is the rate determining step.

\subsection{Activation Energy}

The relationship between the rate constant $\mathrm{k}_{\mathrm{d}}$ and the temperature is given by the Arrhenius equation given by the expression;

$$
\mathrm{k}_{\mathrm{d}}=\mathrm{A} \exp ^{(-\mathrm{Ea} / \mathrm{RT})}
$$

where $\mathrm{A}$ is the frequency factor and $\mathrm{Ea}$ is the apparent activation energy.

The rate constants were calculated from Figure 5 which is the slopes from the graph and are given in Table 5 . To determine the activation energy for the dissolution of the iron ore in $\mathrm{HCl}-\mathrm{HNO}_{3}$ system, an arrehnius graph of $\operatorname{lnk}_{\mathrm{d}}$ vs $1 / \mathrm{T}\left(\mathrm{K}^{-1}\right)$ was plotted which an $\mathrm{Ar}$ rhenius plot is obtained and the activation energy also obtained from the slope of the graph (Figure 6) using Equation (4) to obtain Equation (5).

$$
\mathrm{k}_{\mathrm{d}}=\ln \mathrm{A}-\mathrm{Ea} / \mathrm{RT}
$$

This is equivalent to $y=m x+c$ and therefore the slope from the graph of $\operatorname{lnk}_{d}$ vs $1 / T\left(K^{-1}\right)$ is equivalent to $E_{a} / R$, which means $\mathrm{E}_{\mathrm{a}}=$ slope $\times \mathrm{R}$.

From Figure 6 the apparent activation energy was calculated to be $20.46 \mathrm{~kJ} / \mathrm{mol}$ which is within the range of activation energy for product layer diffusion controlled mechanism.

\subsection{Order of Reaction}

The results from the effect of acid concentration in Figure 1, was applied to Equation (2) which is the product layer diffusion controlled process as was determined to be the mechanism for the reaction and the results are recorded in Table 6. They were used in making a plot against time in Figure 7 to obtain the $\mathrm{k}_{\mathrm{d}}$ values.

The $k_{d}$ values were used to plot a graph of $\operatorname{lnk}_{d}$ vs $\ln \left[\mathrm{HCl}-\mathrm{HNO}_{3}\right]$ as shown in Figure 8 from which the 


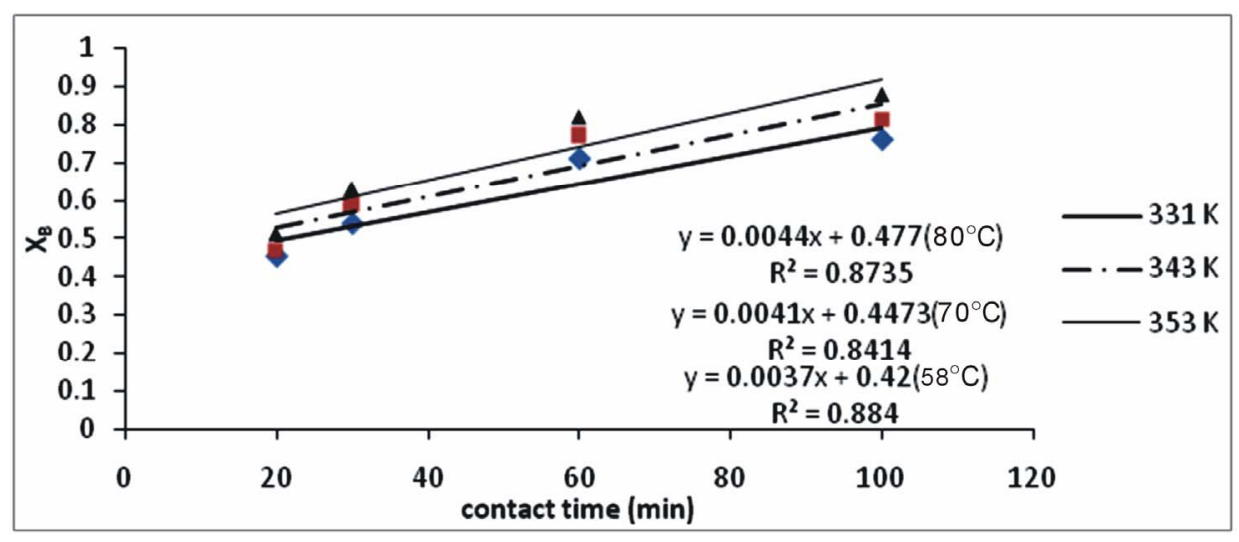

Figure 3. Plot of $X_{B}$ vs contact time with respect to temperature.

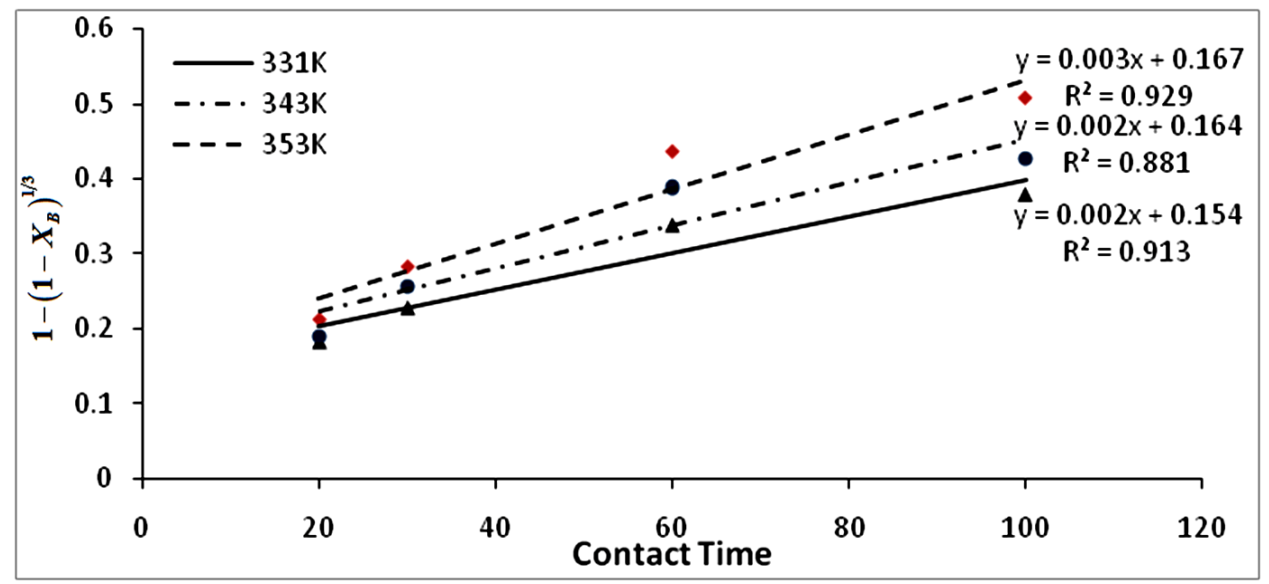

Figure 4. Plot of $1-\left(1-X_{B}\right)^{1 / 3}$ vs contact time (min) with respect to temperature.

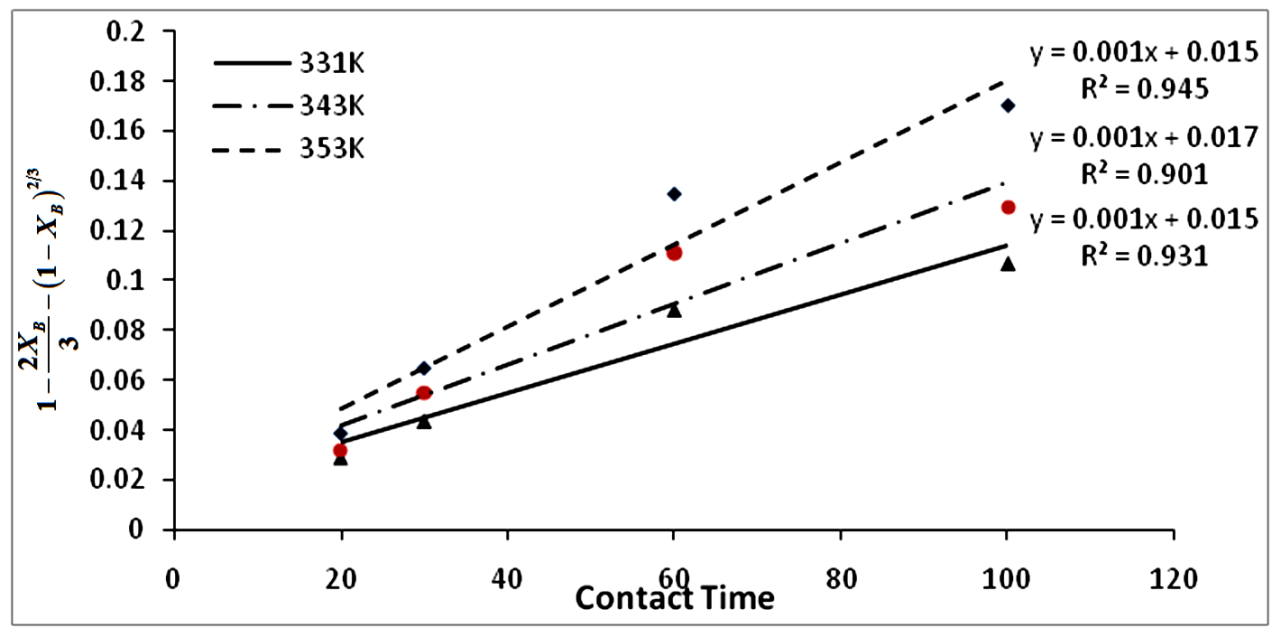

Figure 5. Plot of $1-\frac{2 X_{B}}{3}-\left(1-X_{B}\right)^{2 / 3}$ vs contact time (min) with respect to temperature.

order of reaction was calculated to be the slope of the plot and equal to 0.7 . Therefore the order of reaction for the dissolution of the iron ore in $\mathrm{HCl}-\mathrm{HNO}_{3}$ solution is 0.7 indicating a pseudo first order reaction.

\section{Conclusion}

From the kinetic evaluation for the dissolution of iron ore (obtained from Toto Muro iron ore deposit in Nasarawa 
Table 3. Data of three control mechanisms at varying times with respect to temperature.

\begin{tabular}{lcccc}
\hline$X_{B}$ & $1-\frac{2 X_{B}}{3}-\left(1-X_{B}\right)^{2 / 3}$ & $1-\left(1-X_{B}\right)^{1 / 3}$ & Time (min) & Temp (K) \\
\hline 0.46 & 0.03 & 0.18 & 20 & 331 \\
0.47 & 0.03 & 0.19 & 20 & 343 \\
0.51 & 0.04 & 0.21 & 30 & 353 \\
0.54 & 0.04 & 0.23 & 30 & 331 \\
0.59 & 0.05 & 0.26 & 30 & 343 \\
0.63 & 0.06 & 0.28 & 60 & 353 \\
0.71 & 0.09 & 0.34 & 60 & 331 \\
0.77 & 0.11 & 0.39 & 60 & 343 \\
0.82 & 0.13 & 0.44 & 100 & 353 \\
0.76 & 0.11 & 0.38 & 100 & 331 \\
0.81 & 0.13 & 0.43 & 100 & 343 \\
\hline
\end{tabular}

Table 4. Apparent rate constants $k_{f}, k_{r}$, and $k_{d}$ and their respective correlation coefficient, $R^{2}$ values at various temperature.

\begin{tabular}{ccccccc}
\hline & \multicolumn{3}{c}{ Apparent rate constants $\left(\min ^{-1}\right)$} & \multicolumn{3}{c}{ Correlation coefficient $\left(\mathrm{R}^{2}\right)$} \\
\cline { 2 - 7 } Temperature $(\mathrm{K})$ & $\mathrm{k}_{\mathrm{f}}$ & $\mathrm{k}_{\mathrm{r}}$ & $\mathrm{k}_{\mathrm{d}}$ & $\mathrm{k}_{\mathrm{f}}$ & $\mathrm{k}_{\mathrm{r}}$ & $\mathrm{k}_{\mathrm{d}}$ \\
\hline 331 & 0.0038 & 0.0024 & 0.0010 & 0.8840 & 0.9131 & 0.9313 \\
343 & 0.0041 & 0.0029 & 0.0012 & 0.8414 & 0.8818 & 0.9018 \\
353 & 0.0044 & 0.0036 & 0.0016 & 0.8735 & 0.9293 & 0.9450 \\
\hline
\end{tabular}

Table 5. Rates constant values $k_{d}$ for the dissolution of the iron ore in $\mathrm{HCl} / \mathrm{HNO}_{3}$ at various temperature.

\begin{tabular}{cccc}
\hline $\mathrm{K}$ & $\operatorname{lnk}$ & $\mathrm{T}(\mathrm{K})$ & $1 / \mathrm{T}\left(\mathrm{K}^{-1}\right)$ \\
\hline 0.001 & -6.90776 & 331 & 0.003021 \\
0.0012 & -6.72543 & 343 & 0.002915 \\
0.0016 & -6.43775 & 353 & 0.002833 \\
\hline
\end{tabular}

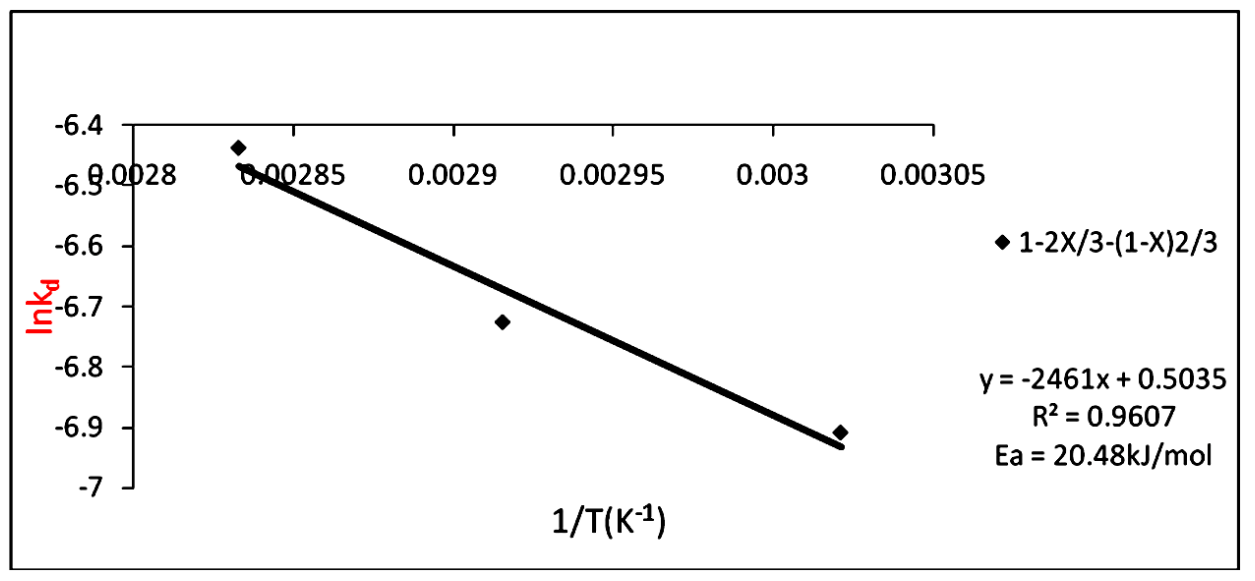

Figure 6. Arrhenius plot of $\ln k_{d}$ vs $1 / T\left(K^{-1}\right)$ for product layer diffusion controlled mechanism. 
Table 6. Product layer diffusion control mechanism at various concentrations.

\begin{tabular}{|c|c|c|c|c|}
\hline Time (min) & Concentration (M) & Quantity leached (\%) & $X_{B}$ & $1-\frac{2 X_{B}}{3}-\left(1-X_{B}\right)^{2 / 3}$ \\
\hline 20 & 1 & 39 & 0.39 & 0.020739 \\
\hline 30 & & 42 & 0.42 & 0.024519 \\
\hline 50 & & 48 & 0.48 & 0.033351 \\
\hline 60 & & 49 & 0.49 & 0.035001 \\
\hline 20 & 2 & 44 & 0.44 & 0.027267 \\
\hline 30 & & 48 & 0.48 & 0.033351 \\
\hline 50 & & 51 & 0.51 & 0.038467 \\
\hline 60 & & 53 & 0.53 & 0.042164 \\
\hline 20 & 4 & 52 & 0.52 & 0.040286 \\
\hline 30 & & 55 & 0.55 & 0.046103 \\
\hline 50 & & 59 & 0.59 & 0.054772 \\
\hline 60 & & 64 & 0.64 & 0.067274 \\
\hline 20 & 8 & 62 & 0.62 & 0.062034 \\
\hline 30 & & 67 & 0.67 & 0.075794 \\
\hline 50 & & 74 & 0.74 & 0.099303 \\
\hline 60 & & 81 & 0.81 & 0.129502 \\
\hline
\end{tabular}

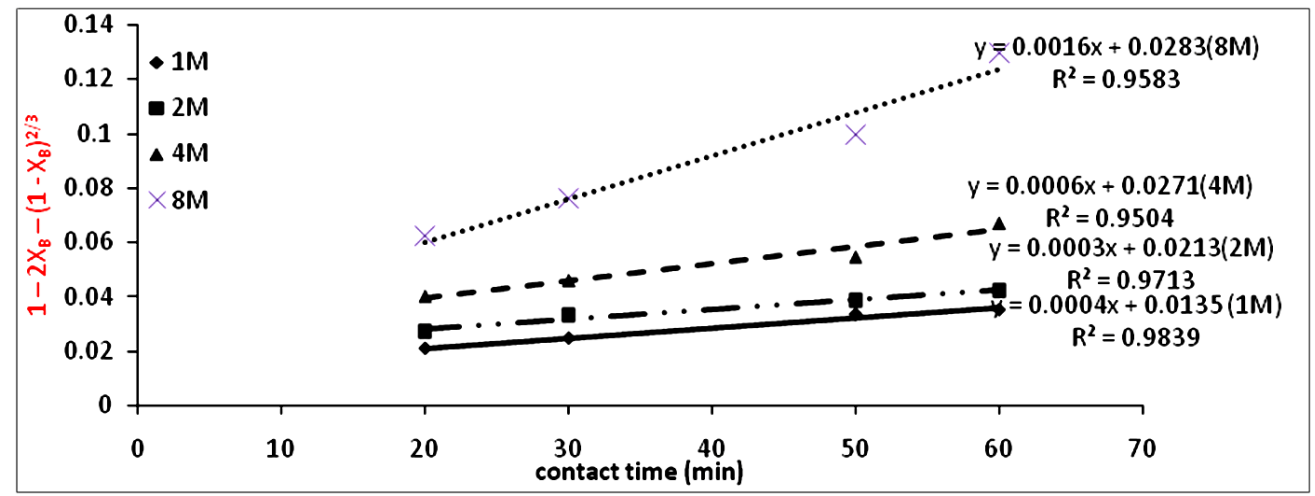

Figure 7. Plot of $1-2 X_{B}-\left(1-X_{B}\right)^{2 / 3}$ vs contact time (min) at various aqua-regia concentration.

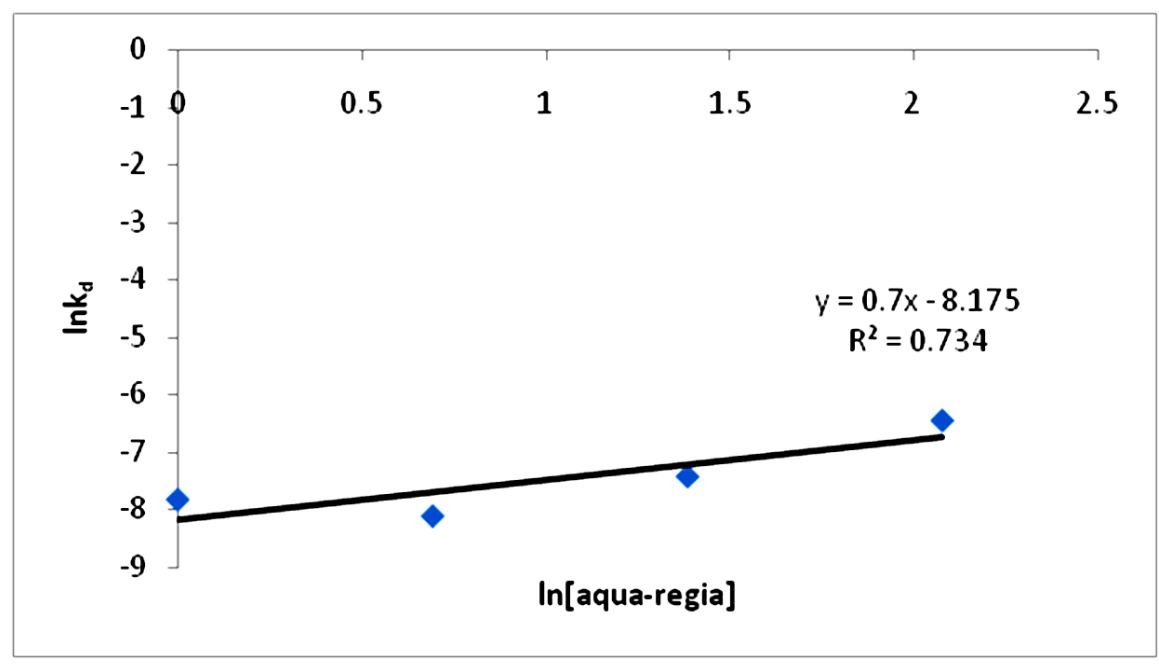

Figure 8. Plot of $\ln k_{d}$ vs $\ln \left[\mathrm{HCl}-\mathrm{HNO}_{3}\right]$. 
State) in $\mathrm{HCl}-\mathrm{HNO}_{3}$ solution, it was observed that the rate of dissolution increases with increasing system concentration, temperature, and time but with decreasing particle size. The optimum conditions for the effective dissolution of $88 \%$ of the iron ore in $\mathrm{HCl}-\mathrm{HNO}_{3}$ solution were obtained at concentration of $8 \mathrm{M}$, temperature of $353 \mathrm{~K}$, and contact time of $100 \mathrm{~min}$ and particle size of less than $75 \mu \mathrm{m}$. Also the reaction was found to be controlled by the product layer diffusion controlled process and this conformed to the shrinking core model equation: $k_{f} t=1-\frac{2 X_{B}}{3}-\left(1-X_{B}\right)^{2 / 3}$. The apparent Activation energy $\left(E_{a}\right)$ and the order of reaction for the dissolution of 1 $\mathrm{g}$ of the iron ore in $\mathrm{HCl}-\mathrm{HNO}_{3}$ system were found to be $20.48 \mathrm{~kJ} / \mathrm{mol}$ and 1 respectively.

\section{REFERENCES}

[1] A. A. Baba, F. A. Adekola and A. J. Lawal, "Investigation of Chemical and Microbial Leaching of Iron Ore in Sulphuric Acid," Journal of Applied Sciences and Environmental Management, Vol. 11, No. 1, 2007, pp. 39-44.

[2] A. A. Baba, F. A. Adekola, and A. O. Folashade, "Quatitative Leaching of a Nigerian Iron ore in Hydrochloric acid," Journal of Applied Sciences and Environmental Management, Vol. 9, No. 3, 2005, pp. 15-20.

[3] A. A. Baba, A. A. Folahan, A. A. Olayide, I. Lateef, B. B. Rafiu, K. G. Malay and R. S. Abdul, "Simultaneous Recovery of Total Iron and Titanium from Ilmenite Ore by
Hydrometallurgical Processing," Metallurgical and Materials Engineering, Vol. 18, No. 1, 2012, pp. 67-78.

[4] G. Gülfen, M. Gülfen and A. O. Aydam, "Dissolution Kinetics of Iron from Diasporic Bauxite in Hydrochloric Acid Solution," Indian Journal of Chemical Technology, Vol. 13, No. 4, 2006, pp. 386-390.

[5] A. Martinez-Luévanos, M. G. Rodriguez-Delgado, A. Uribe-Salas, F. R. Carrillo-Pedroza and J. G. OsunaAlarcon, "Leaching Kinetic of Iron from Low-Grade Kaolin by Oxalic Acid Solutions," Applied Clay Science, Vol. 51, No. 4, 2011, pp. 473-477. doi:10.1016/i.clay.2011.01.011

[6] O. Levenspiel, "Chemical Reaction Engineering," 3rd Edition, John Wiley and Sons Inc., New York, 1999, pp. 566-582.

[7] S. Yagi and D. Kunnii, 5th Symposium (International) on Combustion, In: O. Levenspiel, Ed., Chemical Reaction Engineering, 3rd Edition, John Wiley \& Sons, New York, p. 231.

[8] S. Yagi, D. Kunnii, Chemical Engineering Science, Vol. 16, In: O. Levenspiel, Ed., Chemical Reaction Engineering, 3rd Edition, John Wiley \& Sons, New York, pp. 364 380 .

[9] H. Su, H. Liu, F. Wang, X. Lu and Y. Wen, "Kinetics of Reductive Leaching of Low-Grade Pyrolusite with Molasses Alcohol Wastewater in $\mathrm{H}_{2} \mathrm{SO}_{4}$," Chinese Journal of Chemical Engineering, Vol. 18, No. 5, 2010, pp. 730735 . 